Revista de la Escuela de Ciencias de la Educación, año 12, nRo. 11, vol. 2, Julio a diciembre de 2016. Páginas 239241. ISSN 1851-6297 - ISSN 2362-3349 (En LíneA) ACERCA dE LAS JoRnAdAS ACADÉmiCAS HeAR 2015. Gabriela CRuder

\title{
ACERCA DE LAS JORNADAS ACADÉMICAS HEAR 2015
}

\author{
Gabriela Cruder* \\ Universidad Nacional de Luján, Argentina. \\ gcruder@yahoo.com.ar
}

Recibido: 31/03/2016 Aceptado: 15/05/2016

El día 4 de noviembre de 2015, un nutrido grupo de estudiantes, profesores e investigadores participamos de una Jornada de trabajo en la Facultad de Humanidades y Artes de la Universidad Nacional de Rosario. La convocatoria nos reunió con motivo de formalizar un ámbito de reflexión interdisciplinaria: la presentación a la comunidad académica del Centro de Estudios en Historia de la Educación Argentina Reciente (HEAR-UNR).

Las Jornadas Académicas HEAR tuvieron el objetivo de "incentivar la reflexión conjunta, la socialización y la circulación de producciones y proyectos de investigación en curso provenientes de universidades nacionales e institutos de nivel superior".

La Jornada de trabajo tuvo un intenso programa de actividades que se inició con un panel de presentación del Centro HEAR - UNR. Coordinado por la Prof. Verónica Zamudio, la instancia de apertura contó con las exposiciones de la Dra. Liliana Pérez, el Dr. Adrián Ascolani, el Prof. Rubén Chababo y la Dra. Carolina Kaufmann. Además de destacar el objetivo de la convocatoria, y desde distintas vertientes para su abordaje, los panelistas expusieron en torno de la importancia, las certezas y las tensiones de los estudios y las acciones en relación con la historia reciente y la memoria, haciendo anclaje en las propias experiencias profesionales e institucionales como en el contexto

Profesora para la Enseñanza Primaria y Profesora Especializada en Educación Preescolar. Licenciada en Ciencias de la Educación (UNLu). Cursó estudios de Posgrado en Antropología Social en el Instituto Nacional de Antropología y Pensamiento Latinoamericano. Doctora en Ciencias de la Educación (UBA). Se desempeñó en los distintos niveles del sistema educativo de la provincia de Buenos Aires, ha dictado seminarios de posgrado y actualmente es Profesora Adjunta Ordinaria, responsable del seminario: "Lenguajes y utilización de los medios en la educación", en la UNLu. Cuenta con publicaciones en el área de medios, educación, libros de texto e imagen. 
Revista de la Escuela de Ciencias de la Educación, año 12, nRo. 11, vol. 2, julio a diciembre de 2016. PÁginas 239241. ISSN 1851-6297 - ISSN 2362-3349 (EN LiNEA) ACERCA DE LAS JORNADAS ACAdÉmiCAS HEAR 2015. GABRIELA CRUdER

socio-político-cultural que las enmarca. En ese momento de la jornada de trabajo y por las características de los expositores, la localía de los panelistas, tuvo un papel estratégico dado que permitió conocer a los concurrentes la trama en la que se origina y organiza el Centro, desde la polifonía de las voces convocadas.

A continuación, moderado por la Dra. Silvia Roitenburd los concurrentes tuvimos oportunidad de escuchar las exposiciones de la Dra. Graciela Carbone, la Dra. Laura Rodriguez y el Prof. Gonzalo de Amézola. Cada uno de ellos contribuyó con líneas de reflexión en torno de la historia reciente y sus relaciones con el campo educativo. Los títulos de las presentaciones realizadas, en el orden en el que he mencionado a los panelistas, dan cuenta de los ejes abordados por cada uno de ellos: "Políticas curriculares y libros de texto", "Historia reciente de la Educación: balances y aportes para el estudio de la universidad argentina" e "Historia escolar, historia reciente y formación de ciudadanos."

La trama de las exposiciones configuró un estado del arte, luego se abrió una instancia de preguntas y comentarios, y se generó un intercambio entre los panelistas y la audiencia. En este caso, la diversa procedencia institucional y territorial de los expositores también permitió anticipar lo que sucedería en horas de la tarde, cuando se desarrolló el ateneo sobre experiencias de investigación y trabajos en curso en Historia de la Educación Argentina Reciente.

Como si se tratara de una preparación que aguarda tomar forma definitiva conforme se sumaban las voces, las exposiciones presentadas en el ateneo nos permitieron volver sobre los intercambios iniciados en el panel inaugural, en torno de los tres ejes de trabajo focalizados: historia y política educacional argentina reciente; enseñanza de la historia reciente, y el estudio de los libros de texto.

Durante el desarrollo del ateneos se presentaron once trabajos. Los lectores de esta reseña que se encuentren interesados en conocer las temáticas y los autores de los textos presentados, pueden consultarlos ingresando a la página del Centro -www.hear.unr.edu.ar-.La dinámica del ateneo consistió en una breve exposición de cada participante y, luego, hubo un tiempo reservado para preguntas y comentarios.

Para cerrar las intervenciones, el Dr. Garcés se encargó de exponer su lectura de las presentaciones que escuchamos a lo largo de la tarde, y lo hizo destacando los aportes de los trabajos de los participantes, y compartiendo reflexiones en torno de los temas abordados, transmitió la pasión por el estudio de la historia.

A continuación, la presentación de los programas de investigación nos permitió conectarnos con el trabajo de equipos que, no sin esfuerzo, se encuentran recuperando voces, documentos, etc. Tuvimos oportunidad de co- 
Revista de la Escuela de Ciencias de la Educación, año 12, nRo. 11, vol. 2, julio a diciembre de 2016. Páginas 239241. ISSN 1851-6297 - ISSN 2362-3349 (EN LínEA) ACERCA DE LAS JORNADAS ACAdÉmicAS heAR 2015. GABRIELA CRUdeR

nocer el programa de Historia y Memoria de la Universidad Nacional de San Luis, el archivo de Historia Oral Rosario II, y el de Historia y Memoria del Movimiento estudiantil Rosarino, estos últimos asentados en la Universidad Nacional de Rosario y en convenio con HEAR.

En el marco de las exposiciones precedentes, la Jornada de trabajo concluyó con la presentación del libro La Universidad inconclusa. De la Ratio Studiorum a la reforma universitaria en Mendoza (1973-1974), de Martín Aveiro.

Un punto de vista: la lectura del programa de actividades me produjo inquietud. Me preguntaba si podríamos llevar adelante tan nutrida propuesta. El paso de las horas disipó mis dudas, mostrando el compromiso y el interés puestos en juego por los participantes, y que lejos de disminuir se renovaba en los comentarios, consultas e interrogantes que surgían con cada intervención. El encuentro de trabajo que propició la convocatoria se desarrolló evidenciando la persistencia de los esfuerzos de gran parte de los expositores participantes por recuperar lo sucedido en los distintos ámbitos educativos en el momento más oscuro de nuestra historia, de nuestra historia reciente. Los trabajos sobre el tema dieron cuenta de lo necesario que resulta su estudio y el debate que promueven en la actualidad. Los más jóvenes investigadores pusieron de manifiesto con sus textos y reflexiones que se viene haciendo mucho para comprender lo sucedido, que la tarea pendiente también es voluminosa pero, y felizmente, creo que varios de los participantes con más años de trabajo en la universidad partimos de Rosario con una auspiciosa certeza: el relevo está asegurado. 